\title{
Role of Policy in Best-Practice Dissemination: Informal Professional Advice Networks in Canadian Long-Term Care*
}

\author{
Janice M. Keefe, ${ }^{1}$ (D) Lisa Cranley, ${ }^{2}$ Whitney B. Berta, ${ }^{3}$ Deanne Taylor, ${ }^{4}$ Amanda M. Beacom,

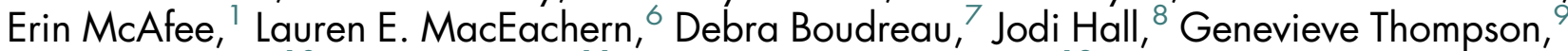 \\ Janet E. Squires, ${ }^{10}$ Adrian Wagg, ${ }^{11}$ and Carole A. Estabrooks ${ }^{12}$
}

\begin{abstract}
RÉSUMÉ
Cet article examine l'influence des politiques provinciales sur les réseaux de conseils professionnels en soins de longue durée (SLD) dans les provinces maritimes au Canada. Les impacts du modèle de propriété des établissements, de la géographie et des contextes politiques régionaux sur la diffusion des meilleures pratiques en matière de soins de longue durée ont été analysés. Des statistiques sociométriques et des sociogrammes de réseaux, calculés à partir d'enquêtes menées auprès de 169 cadres supérieurs d'établissements de SLD, ont été utilisés pour identifier les structures des réseaux de conseils et pour sélectionner 11 participants pour des entretiens de suivi. Les structures des réseaux se sont distinguées par leur densité, le nombre de sous-groupes, les leaders d'opinion et le contrôle des accès. En Nouvelle-Écosse et à l'Île-duPrince-Édouard, cette structure dépendait du modèle de propriété utilisé, tandis que la géographie régionale était un facteur important au Nouveau-Brunswick. L'instabilité politique au sein du système de SLD de chaque province affectait la capacité d'innovation des acteurs du réseau. Les modifications des politiques provinciales influencent les structures des réseaux de conseils en facilitant ou en limitant le développement de relations et le réseautage. Le contexte politique local est un élément déterminant pour l'orientation de la conception et de la mise en œuvre de stratégies de diffusion.
\end{abstract}

\begin{abstract}
This article examines provincial policy influence on long-term care (LTC) professionals' advice-seeking networks in Canada's Maritime provinces. The effects of facility ownership, geography, and region-specific political landscapes on LTC best-practice dissemination are examined. We used sociometric statistics and network sociograms, calculated from surveys with 169 senior leaders in LTC facilities, to identify advice-seeking network structures and to select 11 follow-up interview participants. Network structures were distinguished by density, sub-group number, opinion leader, and boundary spanner distribution. Network structure was affected by ownership model in Nova Scotia and Prince Edward Island, and by regional geography in New Brunswick. Political instability within each province's LTC system negatively affected network actors' capabilities to enact innovation. Moreover, provincial policy variations influence advice-seeking network structures, facilitating and constraining relationship development and networking. Consequently, local policy context is essential to informing dissemination strategy design or implementation.
\end{abstract}

\footnotetext{
Department of Family Studies \& Gerontology, Mount Saint Vincent University

Lawrence S. Bloomberg Faculty of Nursing, University of Toronto

Dalla Lana School of Public Health, University of Toronto

4 Research Department, Interior Health Authority, British Columbia

5 Visible Network Labs, Denver, Colorado

6 Institute for Health Policy, Management and Evaluation, University of Toronto

7 Tideview Terrace Home for Special Care, Digby, Nova Scotia

8 New Brunswick Association of Nursing Homes

9 Rady Faculty of Health Sciences, University of Manitoba

10 School of Nursing, University of Ottawa

11 Division of Geriatric Medicine, University of Alberta

12 Faculty of Nursing, University of Alberta
}

Canadian Journal on Aging / La Revue canadienne du vieillissement 40 (1) : 166-176 (2021)

(c) Canadian Association on Gerontology 2020. This is an Open Access article, distributed under the terms of the Creative Commons Attribution licence (http://creativecommons.org/licenses/by/4.0/), which permits unrestricted re-use, distribution, and reproduction in any medium, provided the original work is properly cited. 
* This work was supported by the Canadian Institutes of Health Research, Partnerships for Health System Improvement (MOP \#318861). Additional partner funding was provided by the Nova Scotia Health Research Foundation, Alberta Innovates Health Solutions, the Michael Smith Foundation for Health Research, and Research Manitoba. We thank Pamela Fancey of the Nova Scotia Centre on Aging for coordinating the production of the manuscript and to the senior leaders throughout Maritime Canada who completed the survey and participated in the interviews.

Manuscript received: / manuscrit reçu : 17/05/2019

Manuscript accepted: / manuscrit accepté : 24/01/2020

Mots-clés: vieillissement, soins de longue durée, analyse de réseaux sociaux, réseaux de conseils informels, recherche sur les systèmes de santé, provinces canadiennes

Keywords: ageing, long-term care, social network analysis, informal advice-seeking networks, health system research, Canadian provinces

La correspondance et les demandes de tirés-à-part doivent être adressées à : / Correspondence and requests for offprints should be sent to:

Janice M. Keefe, Ph.D.

Department of Family Studies \& Gerontology

Mount Saint Vincent University

166 Bedford Highway

Halifax, NS B3M 2J6

(janice.keefe@msvu.ca)

\section{Introduction}

Health system leaders are substantially influenced by interpersonal relationships when considering whether or not to adopt a new practice (Dearing, 2009; Greenhalgh, Robert, Bate, Macfarlane, \& Kyruakidou, 2005; Palinkas et al., 2011). Interpersonal relationships create social networks, which are systems of communication that foster advice seeking among individuals in the networks (Greenhalgh et al., 2005; Palinkas et al., 2011; Valente, Palinkas, Czaja, Chu, \& Hendricks Brown, 2015). Participation in a social network affects communication and advice-seeking behaviours within a particular sector and the subsequent adoption, implementation, and sustainment of new practice (Greenhalgh et al., 2005; Palinkas et al., 2011; Schoen, Moreland-Russell, Prewitt, \& Carothers, 2014). With overt knowledge of social networks' structure and members, internal and external network members can disseminate, or actively influence, the diffusion of innovations within a particular sector (Pow, Gayen, Elliott, \& Raeside, 2012). The successful dissemination of innovations (i.e., a new idea, practice, or product) depends in part on the relationships among multiple stakeholders at different levels (Carter \& CurrieAlder, 2006; Lanham et al., 2013).

In the health sector, the lag between the introduction of the innovation and its adoption creates a pressing need to understand how better to disseminate best practice (Canadian Healthcare Association, 2009; Lucas et al., 2005; Valente et al., 2015). We developed social network maps from eight Canadian provinces and territories and identified, for the first time, advice-seeking patterns (Dearing et al., 2017). Differing network structures among provinces led us to develop the key question of this article: how does provincial policy context influence the structure of informal professional advice networks in LTC? Policy context is here defined as the epidemiological, economic, political, and ideological circumstances in which public policy is formulated (Collins, Green, \& Hunter, 1999; Frenk, 1995. To answer this question, we focused on the three Maritime provinces in Canada and conducted quantitative analysis of interpersonal networks and qualitative analyses of interviews with senior regional leaders. Our objective was to increase understanding of how high-level policy may influence the informal advice networks of LTC professionals, which in turn influence the success of best-practice dissemination in the region.

\section{Long-Term Care Policy Context}

In Canada, long-term care facilities are licensed under a public system of provincial governments: ministries or regional health authorities cover the cost of health services whereas individuals pay food and shelter costs. Facilities operate under one of three ownership models: non-profit public or government operated, non-profit voluntary or faith based, and proprietary for profit.

This article focuses on LTC informal advice-seeking networks in Canada's eastern seaboard provinces, known collectively as the Maritime provinces: Nova Scotia, New Brunswick, and Prince Edward Island. They form a distinct region, characterised by similar land mass, high unemployment rates, high rates of young adult out-migration, and possessing substantially smaller populations relative to other Canadian provinces (see Keefe, MacEachern, \& Fancey, 2017). The Maritime provinces also have the highest proportions of older persons in Canada (Statistics Canada, 2017). 
Table 1: Overview of LTC context in Nova Scotia, New Brunswick, and Prince Edward Island at the time of the survey (Fall, 2014)

\begin{tabular}{|c|c|c|c|}
\hline Descriptor & Nova Scotia & New Brunswick & Prince Edward Island \\
\hline Department responsible & Health and Wellness & Social Development & Health and Wellness \\
\hline Legislative framework & Homes for Special Care Act & Nursing Home Act & $\begin{array}{l}\text { Community Care Facility and Nursing } \\
\text { Home Act }\end{array}$ \\
\hline Ownership model & $\begin{array}{l}\text { Non-profit public/government } \\
\text { operated; } \\
\text { Non-profit voluntary or faith based; } \\
\text { Proprietary for profit }\end{array}$ & $\begin{array}{l}\text { Non-profit voluntary or faith } \\
\text { based }\end{array}$ & $\begin{array}{l}\text { Non-profit public/government operated; } \\
\text { Non-profit voluntary or faith based; } \\
\text { Proprietary for profit }\end{array}$ \\
\hline \# of facilities & 88 & 66 & 19 \\
\hline \# of beds ${ }^{a}$ & 7,060 & 4,528 & 1,166 \\
\hline Average \# of beds/facility & 80 & 69 & 61 \\
\hline $\begin{array}{l}\text { \# of beds } / 1,000 \text { population aged } \\
65+^{\mathrm{b}}\end{array}$ & 41 & 34 & 43 \\
\hline Administrative structure & 9 health districts & 8 regions & 1 health region \\
\hline
\end{tabular}

Note. ${ }^{a}$ Includes respite beds.

b Population calculation based on Statistics Canada (2017). Estimates of population (2011 Census and administrative data), by age group and sex for July 1st, Canada, provinces, territories, health regions (2015 boundaries) and peer groups. CANSIM Table 1095355. Retrieved from http://www5.statcan.gc.ca/cansim/a26?lang=eng\&id=1095355

Long-term care service delivery is distinct in each Maritime province (see Table 1), as are the composition and structure of LTC senior leaders' advice-seeking networks (Dearing et al., 2017).

\section{Influence of Policy Context on Social Networks}

Substantial literature in political science, public policy, and public administration fields features social network analysis; that is, an analysis of how policy networks, collaboration networks, and governance networks influence the formulation, implementation, and management of a particular policy and its enactment (Berry et al., 2004; Isett, Mergel, LeRoux, Mischen, \& Rethemeyer, 2011; Knoke, 2011; Lecy, Mergel, \& Schmitz, 2014; Rhodes, 2006). Much of this literature has focused on formal networks, particularly collaboration and governance networks (Isett et al., 2011). Less common are studies that examine how public policy, and the policy context, influence the structure of a particular sector's informal network of stakeholders (Berry et al., 2004; Knoke, 2011; O'Toole, 2015). This question is sometimes indirectly addressed by researchers interested in the wider environmental context (see Greenhalgh et al., 2005) affecting the diffusion or intentional dissemination of a given innovation, but such work does not always examine how policy influences network structures, which in turn may influence dissemination processes. The influence on network structures is our focus, and primary contribution, of this article.

Evidence suggests that policy context can influence the composition and structure of LTC social networks and their homophily in terms of LTC facility ownership, geographic proximity, and the political landscape. Homophily - a high rate of contact between similar people - is a driving factor in relationships and social network development (Mascia, Di Vincenzo, Iacopino, Fantini, \& Cicchetti, 2015; Rogers, 1983). The similarities that connect people in professional networks fall into a range of categories, including age, gender, attitudes, education, profession and job title, and employer, as well as specific employers' characteristics such as organisation size and type (Mascia et al., 2015; McPherson, Smith-Lovin, \& Cook, 2001; Yaraghi et al., 2014). Research suggests that individuals prefer advice relationships with homophilous colleagues in a professional network because of the likelihood of a common base of knowledge and understanding, and because colleagues are often simply easier to approach (Darr \& Kurtzberg, 2000; Ferlie, Fitzgerald, Wood, \& Hawkins, 2005; Szulanski, 1996; von Hippel, 1994).

High rates of contact in a network are also observed where individuals are geographically proximal (Phelps, Heidl, \& Wadhwa, 2012; Reagans, 2011). Research suggests two reasons for this influence. First, despite advances in technology, face-to-face contact remains an important and often primary source of communication (McPherson et al., 2001; Yaraghi et al., 2014). Second, regionalisation and policy or governance structures that reinforce regional boundaries or distinctions may inhibit network development. Giddens (1985) has referred to regionalisation as the consequence of social conduct particular to a geography that becomes routinised over time and space to emerge as social practices (or norms) esoteric to that region or geography. Although the potential influence of regional structures can support or inhibit network development, it is nonetheless understudied in social network literature (Kim \& Shin, 2002).

Political landscape features also influence network structure: changes in legislation and governance 
systems, "focusing events" such as terrorism attacks, disruptive innovations, and interest groups and professional membership associations (Knoke, 2011). Given our understanding about factors that influence social networks, there is merit to investigate how these influences play out within LTC in Canada's Maritime provinces.

\section{Study Purpose}

To examine the potential influence of provincial policy on advice-seeking networks, in our study we sought to (a) examine the structure of informal advice-seeking networks among LTC leaders in three Maritime provinces in Canada, (b) identify contextual factors that might underlie distinctions among interpersonal networks, and (c) discuss implications of network differences across provincial policy contexts for best-practice dissemination in the three Maritime provinces.

\section{Methods}

We adopted a mixed-methods approach, utilising quantitative and qualitative data to gain a broader, deeper understanding of advice networks' structure, antecedents, and consequences. We integrated the two data types using a sequential explanatory design (Domínguez \& Hollstein, 2014), in which we collected and analysed quantitative survey data, and used those results to guide collection and analysis of qualitative interview data, which in turn helped contextualise and explain the quantitative results. We obtained ethics clearance from the Research Ethics Office (REO) at the University of Alberta (file number Pro00050958) and the University Research Ethics Board at Mount Saint Vincent University (MSVU) (file number 2014-043).

\section{Quantitative}

Data Collection. We collected quantitative data using a sociometric survey of 169 senior leaders in each of the long-term care facilities operating in the Maritime provinces in 2014. The survey was distributed online to one senior leader per facility, typically the facility director of care or director of nursing, having decision-making responsibility for implementation of best practice. In some cases, senior leaders had responsibility for more than one facility and completed the survey on behalf of all the facilities for which they were responsible. We assessed interpersonal advice-seeking behaviour by asking respondents to provide the names of three individuals, external to their facility, whose advice they have sought or whose behaviour they have monitored with regard to delivery of quality care, care improvement, and innovation.
Other data on health region and ownership were obtained through sector representatives (see Dearing et al., 2017).

Analysis. We used descriptive statistics (SPSS v23) to assess employment and demographic data, and generated sociometric statistics and network sociograms from the advice-seeking data using UCINET version 6 and Gephi version 0.9 software. We identified opinion leaders and boundary spanners in each provincial network. Opinion leaders are popular actors with whom many seek to form a relationship. Boundary spanners, individuals who connect two or more groups in the larger network, are significant for their ability to span structural gaps between disconnected individuals. We have constructed density scores for each network from the number of ties actually present divided by the number of all ties theoretically possible between actors in the network. For additional information about the survey data collection and analysis procedures, see Dearing et al. (2017).

\section{Qualitative}

Data Collection. We conducted 11 interviews with opinion leaders, boundary spanners, and advice seekers from LTC sectors in Nova Scotia $(n=6)$, New Brunswick $(n=4)$, and Prince Edward Island $(n=1)$. Participants were purposively identified based on network position (e.g., centrality score) and role (e.g., opinion leader, boundary spanner, advice seeker). Each 30- to 70-minute interview was conducted by two team members between September 2015 to May 2016, all but one by telephone. Interview questions addressed the nature of the advice-seeking relationship, motivations for seeking or providing advice and information, and characteristics of highly sought-after opinion leaders. We pretested interview guides and transcribed each interview with identifiers removed to protect participant confidentiality.

Analysis. Four researchers independently reviewed each transcript, and then participated in three consensus coding sessions to uncover new knowledge based on the study's research questions. We applied a systemlevel lens to help uncover region-specific information about the LTC political landscape, to learn if and how provincial governing bodies and associations influence social networks, to discover types of information that may pass through the network, and to reveal influential formal and informal gathering events (e.g., annual meetings, conferences) important to the overall network functioning. Analysis also aimed to find references to influential system events that may strengthen social networks or inform participants of key initiatives in innovation implementation or circulation. Interview examples are presented collectively to reflect the 


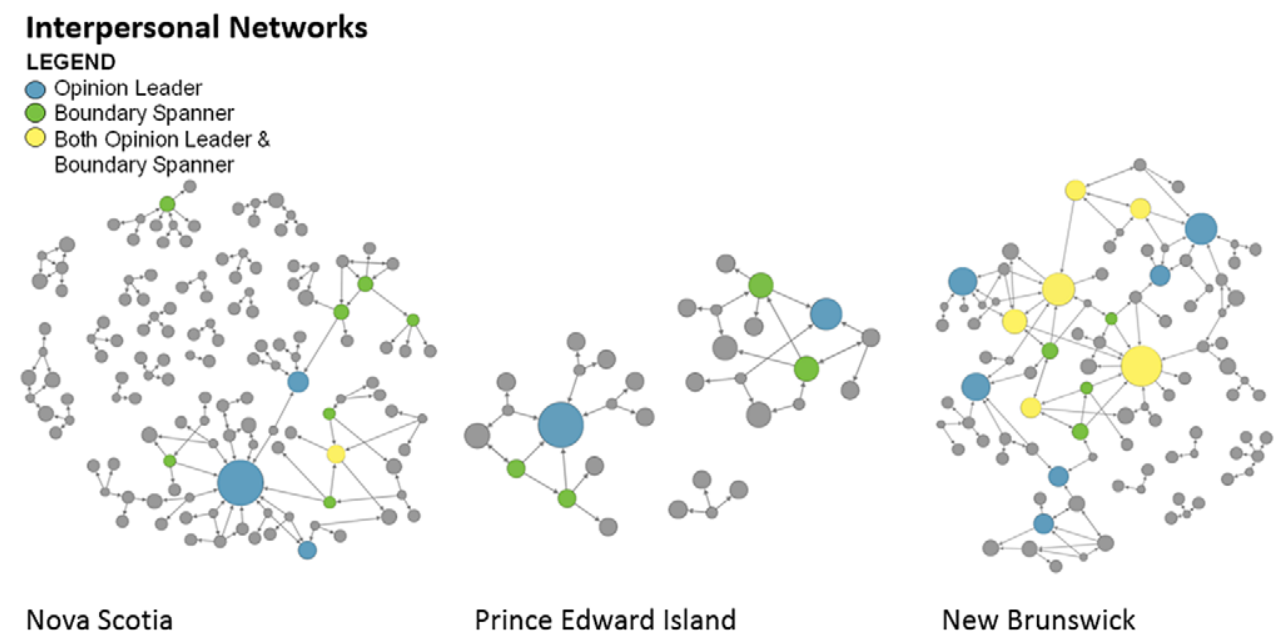

Figure 1: Interpersonal network maps of the three Maritime provinces

(Nova Scotia, Prince Edward Island, New Brunswick)

Maritimes' perspective. For additional information about the data collection and analysis procedure, see Cranley et al. (2019).

\section{Results}

Across the three Maritime provinces, the survey response rate was 67 per cent with individual response rates of 60 per cent in Nova Scotia, 74 per cent in New Brunswick, and 75 per cent in Prince Edward Island. Demographic and employment characteristics were similar: the majority of respondents were women $(81 \%)$, aged 40 to $59(74 \%)$, with a professional nursing background (96\%). Their work experience in the LTC sector averaged 15 years, and in their current position, seven years.

\section{Composition and Structure of Maritime Networks}

Two similarities were seen in the networks' composition and structure: provincial silos in LTC best-practice information exchanges, and the likelihood of other sector stakeholders acting as provincial advice providers. Only two individuals across the three networks sought advice from colleagues in other provinces, and more than one third ( $38 \%$ to $44 \%$ ) of the nominated individuals to offer advice included those with positions in corporate offices of LTC facility organisations, regional health authorities and provincial governments, and sector consultant or expert roles. Directors of care were found to have advice-seeking relationships with contracted service providers and personnel in government and facility pharmaceutical service delivery, indicating informal relationships beyond the expected scope of practice. Network structures demonstrated that best-practice information is obtained provincially from diverse actors often outside the LTC facility.
Significant variance emerged in network structure among the three Maritime provinces, as shown in network sociograms of the provinces (Figure 1). In Nova Scotia, 50 individuals reported seeking advice from 101 sources. The network was dominated by one central opinion leader; this highly centralised structure was distinct from the other Maritime provinces and all of the 11 provinces and territories analysed within the larger study (Dearing et al., 2017). With a moderate degree of interconnectedness (e.g., 0.007 compared to Prince Edward Island which was more densely connected, 0.036), Nova Scotia had one large sub-group of individuals, with many smaller, disconnected clusters.

In New Brunswick, 47 individuals reported seeking advice from 73 sources. New Brunswick's advice network was characterised by one almost entirely interconnected sub-group, with an overall density of 0.014 and only 16 individuals (17\% of network actors) outside of this main sub-group. Unlike the Nova Scotia network, opinion leadership within New Brunswick was dispersed across many individuals. The sociograms of Nova Scotia and New Brunswick show the significance of boundary spanners, who bridge the gap between different network subgroups.

The sociogram (Figure 1) for Prince Edward Island shows 13 individuals seeking advice from 25 sources. The province's advice network was characterised by two large, distinct subgroups, both of which surrounded one dominant opinion leader. Additionally, there was one small cluster of individuals not connected to the two dominant sub-networks.

To understand these structural differences, we turned to three features of the Canadian LTC policy context: ownership homophily, geographic proximity, and political landscape. 


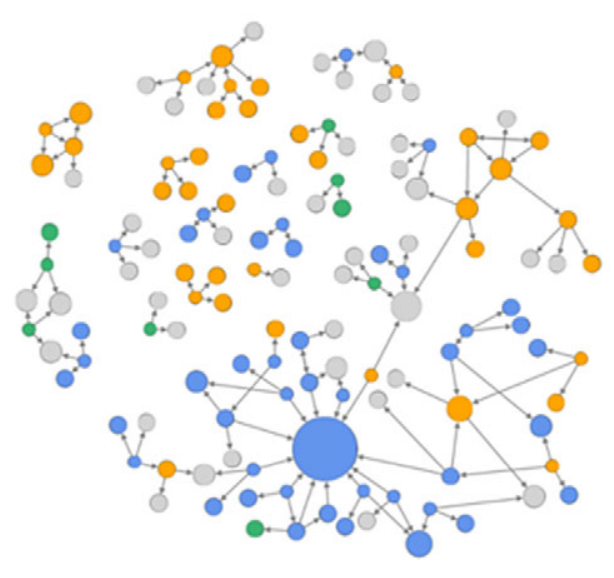

Figure 2: Interpersonal network map of Nova Scotia

(coded by owner-operator model)

\section{Ownership Homophily}

We observed evidence for the influence of ownership homophily on advice networks in Nova Scotia and Prince Edward Island, where multiple facility ownership models existed (New Brunswick was the sole nonprofit model). In Nova Scotia, the dominant opinion leader identified in the network was an individual who works for a chain of private, for-profit LTC facilities (Figure 2). Those who sought advice from this opinion leader were colleagues also working for private forprofit facilities (depicted by blue circles). Additionally, the sociogram shows the clustering of individuals who worked for voluntary non-profit facilities (depicted by orange circles). These patterns of affiliation suggest ownership homophily strongly influenced adviceseeking behaviour in Nova Scotia.

As illustrated in Figure 2, senior leaders in LTC facilities established advice relationships with colleagues in other LTC facilities with a similar ownership structure, or with individuals in the sector working outside a specific LTC facility, such as those holding LTC-related health authority or provincial government positions. The role of the Community Governed Nursing Home Society of Nova Scotia (CGO), discussed by interview participants, spoke to this influence of ownership; the CGO allows Nova Scotian non-profit nursing homes to connect and share information. This association was identified in interviews as an entity that fostered relationships among professionals in non-profit LTC facilities, making advice seekers more comfortable to reach out for advice:

[I] also have some connection with [boundary spanner] through the CGO group. So again, having that relationship and knowing her, I do feel comfortable to reach out to her if I have questions as well, even though they are bigger nursing homes than we are. P02 (advice seeker)
The network map for Prince Edward Island also suggested a strong ownership homophily effect. This provincial advice network was characterised by two large subgroups, both of which surrounded one dominant opinion leader who worked in a regional or provincial position outside of an LTC facility (e.g., consultant, liaison officer) (Figure 3), and connected within their respective networks by several key boundary spanners (see green dots in Prince Edward Island sociogram in Figure 1).

As depicted in Figure 3, the sub-group on the left is composed exclusively of leaders working in publicly owned and operated facilities (depicted by green circles), while the sub-group on the right is composed primarily of leaders working in privately owned and operated facilities (depicted in blue). Individuals based in corporate or regional/provincial positions were present in both subgroups of the network (depicted in grey). This ownership effect is reinforced by the provincial LTC policy structure, in which the provincial Ministry of Health regulates non-profit and for-profit LTC facilities separately. In Nova Scotia, despite its mixed ownership model, regulations do not differentiate by ownership.

\section{Geographic Proximity}

Geographic proximity appears to exert an influence on the structure of the advice-seeking networks in both Nova Scotia and New Brunswick, with the strongest effect in the latter province. As illustrated by the colourcoding in Figure 4, New Brunswick individuals tended to seek advice from colleagues in their local region. In Nova Scotia, the effect of geographic proximity was less noticeable due to the stronger role of ownership in its network composition. In Prince Edward Island, we observed no geographic influence on the network, 


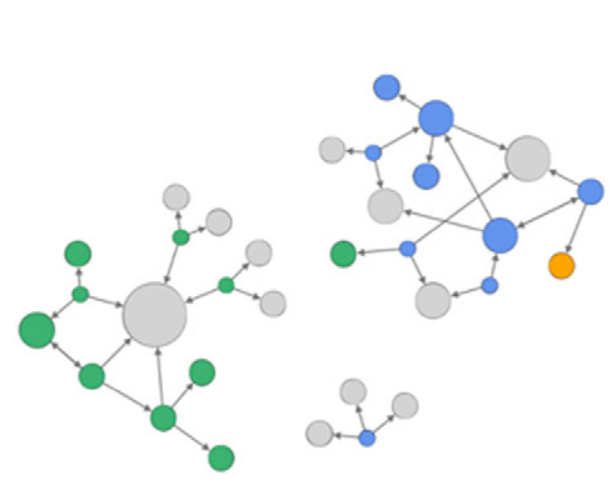

Figure 3: Interpersonal network map of Prince Edward Island

(coded by owner-operator model)

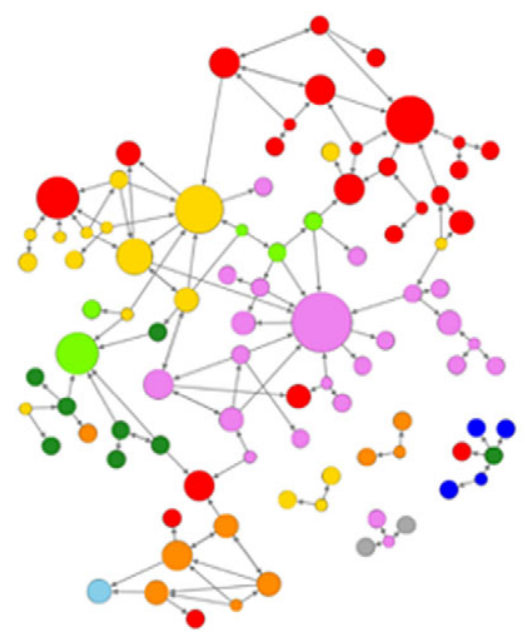

Figure 4: Interpersonal network map of New Brunswick

(coded by Social Development region)

which is understandable given its size and single administrative health region.

\section{Political Landscape}

Changes in provincial government were found to impede administrators' ability to implement new programmes or innovations, due to shifting relationships with government actors:

In New Brunswick, we seem to vote somebody new in, every couple years. So things that are coming down the line and what - and as administrators, that we are made aware of, I just find it never goes through, because people in New Brunswick change parties every few years. - P66 (advice seeker)

The inconsistency of provincial-level actors may be contributing to an increasingly localised network. In Nova Scotia, there was evidence that strong network leaders with longstanding experience and knowledge
LEGEND

Public not-for-profit facility

Voluntary not-for-profit facility

Private for-profit facility

Works outside LTC facility

\author{
LEGEND \\ Region 1 (Moncton) \\ $\bigcirc$ Region 2 (Saint John) \\ Region 3 (Fredericton) \\ Region 4 (Edmundston) \\ O Region 5 (Restigouche) \\ Region 6 (Chaleur) \\ Region 7 (Miramichi) \\ Region 8 (Acadian Peninsula) \\ Outside NB
}

garnered through sector changes may mitigate challenges associated with shifting political landscapes:

She has seen a lot of changes that Department of Health has put into place. And so, through her experience and knowledge of the placement and how long-term care works and functions, I seek her knowledge base. - P20 (advice seeker)

We found that communication trends within social networks were influenced by provincial political landscape changes and also relationships with provincial organisations. For example, through sharing learning opportunities and hosting conferences, we noted that the Atlantic Institute on Aging had helped develop connections within New Brunswick. Changes in local non-profit organisations were also found to affect communication trends. One interviewee spoke to the need for advice when the Victorian Order of Nurses (VON) ceased service provision in New Brunswick: 
VON closed their doors. And they provided a lot of foot care. So you know, a message goes out to all the nurses - all the directors of nursing in the area. Like, "Okay, what are you guys gonna do," or, "Who were you using?" And "do you have any ideas on who we could call to fill that void?" - P23 (advice seeker)

Although former provincial organisations like the VON were able to overcome the geographical constraints noted by New Brunswick participants, their closure left a service gap that advice seekers needed to fill.

\section{Discussion}

This study investigated the potential influence of provincial policy on LTC advice-seeking networks in Canada's Maritime provinces, in order to understand whether policy-driven contexts might underlie network distinctions, and to discuss implications for the dissemination of best practice.

\section{Distinct Structure of Advice-Seeking Networks}

Despite the perception of the Maritime provinces as homogenous, the interpersonal advice-seeking network structures of Nova Scotia, New Brunswick, and Prince Edward Island presented striking differences. As could be assumed from the number of long-term care facilities in each province, we observed more network ties in Nova Scotia and New Brunswick compared to Prince Edward Island.

The number and distribution of key players identified through network ties, such as advice seekers, opinion leaders, and boundary spanners, also differed within each province. Using knowledge of network structure differences, and an understanding of the presence (or absence) of connected persons, dissemination efforts could be targeted to reach their intended audience most efficiently. Observation of distinct network structures across the three provinces reaffirmed our intention to determine whether unique contextual factors were at play in the province and whether the policy context itself may have been a contributing factor.

\section{Influencing Contextual Factors}

Our findings suggest that the policies pertaining to public long-term care system management in the three Maritime provinces exert capability constraints on actors in each of the social networks (Giddens, 1985). The influence of ownership, geography, and politics has implications for the dissemination and spread of innovation.

Ownership of Long-Term Care Facilities. Long-term care facilities' ownership is central to the organisation of social networks, regardless of provincial variation in ownership models. In Nova Scotia, several for-profit owned facilities are involved in the delivery of care in a multi-site approach; it is this chain of private for-profit LTC facilities that account for the "hub" of the province's largest network. In contrast, the LTC facilities in New Brunswick are non-proprietary as a result of the legislative framework. This relative homogeneity of ownership may partially account for New Brunswick's greater network cohesion.

In Nova Scotia, boundary spanners link the corporate "hub" with non-profit facilities. Interview participants discussed how non-profit facilities had been organised into a formalised society of community-governed facilities; this group is evident in the sociogram as a more diffuse sub-group connected to the corporate "hub" through boundary spanners. Participants remark on this society's important role in facilitating connections and fostering relationships. In this way, advice-seeking relationships based on homophily were developed within Nova Scotia's LTC sector. This practice may be particularly important in jurisdictions where corporate entities dominate the long-term care network.

The impact of ownership on network structure is apparent on Prince Edward Island's publicly owned/operated facilities and privately owned/operated facilities. Despite a small number of LTC facilities $(n=19)$, the province has developed separate networks for publicly owned and operated facilities and privately owned and operated facilities; no evidence was found for a boundary spanner between the ownership types. Here, ministerial policies intervene: publicly operated facilities or privately operated facilities are overseen by different liaison officers (who emerged as opinion leaders in each network). Quality assurance regulations are also distinct: private facilities are subject to licensing regulations, whereas public facilities are required to be accredited by Accreditation Canada.

Geographic Proximity. Proximity between network actors leads to more frequent contact and connections (Walker, Wasserman, \& Wellman, 1994). In New Brunswick, senior leaders' geographical region factors into the network structure. We found that directors of care sought advice primarily from within their regions or the one adjacent to them, and very rarely outside the province. This finding supports previous research suggesting that people connect with those in close proximity whom they know, regardless of communication technology resources. Interpersonal connections in person or by telephone remain the primary sources of communication (McPherson et al., 2001; Yaraghi et al., 2014).

The regional structure as defined by provincial ministries may reinforce connectivity with localised geographical spaces. At the time of our data collection, both Nova Scotia and New Brunswick had a 
decentralised regional system of eight or nine regions. The social practices of the past appear to be routinised: despite the province's reconfiguration into one health authority, in Nova Scotia previous regional administrative boundaries still appear to dominate continuing care forums and other educational events. This finding is consistent with Giddens' (1985) characterisation of regionalisation as a phenomenon that shapes social conduct across time and space.

The enduring effects of regional boundaries in Nova Scotia and New Brunswick facilitate rich exchanges, but constrain actors to regionally available innovations and best-practice knowledge. The co-existence of facilitating and constraining system-structural effects on network actors' interactions has long been observed by sociologists (Haines, 1988). Furthermore, network regionalisation may result in certain areas becoming leading areas of innovation and best practice, while others lag behind (Berta et al., 2005). Berta et al. (2005) stated that the number of innovation adopters within the same geographic area is highly influential on the adoptive behaviours of other network actors. Other jurisdictions may want to consider government policies on educational forums, limited travel expenses, and geographically structured organisation, and the implications of this narrow reach of interaction on adoption of best practice.

Political Landscape. Social network analysis has generally examined how public policy is influenced by networks. Our findings suggest otherwise, that the Maritime provinces' policy structures and content influence LTC advice-seeking networks (Berry et al., 2004; Knoke, 2011). Political landscape permutations cannot be discounted when considering dissemination strategies for best practice.

Those in power also affect the landscape of social networks and the potential for innovation dissemination. Interviews with advice seekers illustrate the importance of opinion leaders who are experienced in provincial government fluctuations and subsequent changes in policy direction. The political context and its changing landscape appear to influence the advice-seeking network. For example, changes in administrative funding, sector services, and service delivery philosophy contribute to disruption of the existing network structure and functional effectiveness of professional network members (Provan \& Milward, 1995).

The influence of the political landscape is further evident in that few directors of care seek external provincial advice because network actors are behooved to act within boundaries "drawn" by provincial jurisdiction. One interpretation is that long-term care decisionmaking is politicised, which influences network structure and may even have a trickle-down effect on bestpractice decisions.

\section{Implications for Dissemination of Best Practice in Long-Term Care}

Our research question arose from the possibility that policy context drives distinctions in LTC senior leaders' informal advice-seeking networks. We know that successful spread of best practice depends in part on the relationships among multiple stakeholders at different levels (Carter \& Currie-Alder, 2006; Lanham et al., 2013). This analysis shows that region-specific long-term care policies - here, provincial government policy - may influence LTC network structures on the basis of facility ownership, geography, and political landscape. The different provincial advice-seeking networks are a function of the policy context in which they are embedded.

The question of policy context's influence on networks has been indirectly addressed in some diffusion literature by researchers interested in how the "wider environmental context" (see Greenhalgh et al., 2005) affects the diffusion or intentional dissemination of a particular innovation. Such work, however, does not always provide a detailed examination of specific policy effects on network structures and consequent dissemination processes; that examination is the primary contribution of this article.

Our results suggest that approaches to dissemination should consider and incorporate the local policy context. In Nova Scotia, it would be strategic to target bestpractice dissemination to the opinion leader of the dominant corporation first, then to the opinion leader and boundary spanners of the community governance organisation, and finally to select regional leaders. In New Brunswick, regional leaders should be targeted initially. The dissemination strategy for Prince Edward Island would need to address the overarching policy structure and target provincially appointed opinion leaders in each ownership group. These results have implications for public policy-makers: mechanisms created to administer policies may enable dissemination or act as dissemination barriers.

Another contribution of this article is its comparison of how policy context influences network structure across three separate jurisdictions. Comparative research on policy networks that attempts to draw conclusions beyond the scope of a single case are much needed but rare (Isett et al., 2011; O'Toole, 2015), and our policy comparison is strengthened because of the inclusion of knowledge users familiar with the respective long-term policy contexts. By fully understanding unique contextual factors, health system leaders have an enhanced potential to efficiently disseminate best practices across these three jurisdictions.

More broadly, our results indicate that the ability for networks to successfully spread a new practice is a 
result of multiple layers of contextual variation. Given the variability in the structure of LTC across Canada, it may be strategic for jurisdictions, when attempting to introduce an innovation, to undertake a similar mapping process to understand their respective existing advice-seeking networks. Insights about existing informal communication structures within the organisation, and in regional and provincial policy context, may contribute to successful dissemination of best practices.

\section{Conclusion}

Spreading best practice in clinical care and care delivery effectively and efficiently will improve quality of life in LTC facilities. This article offers additional insight on traditional dissemination patterns based on a mixedmethods approach and a contextual analysis of three Maritime provinces in eastern Canada. It is incumbent on individuals implementing a dissemination strategy, or designing an implementation study, to know the nuances of policy contexts that affect communication channels and the structural features that may impede these efforts.

Our research suggests that public policy and governance structures influence advice-seeking networks and therefore may support or limit the spread of innovation. If so, this has implications for the spread and dissemination of best practice.

\section{References}

Berry, F. S., Brower, R. S., Choi, S. O., Goa, W. X., Jang, H. S., Kwon, M., \& Word, J. (2004). Three traditions of network research: What the public management research agenda can learn from other research communities. Public Administration Review, 64(5), 539-552. doi:10.1111/j. 1540-6210.2004.00402.x.

Berta, W., Teare, G. F., Gilbart, E., Soberman Ginsburg, L., Lemieux-Charles, L., Davis, D., \& Rappolt, S. (2005). The contingencies of organizational learning in long-term care: Factors that affect innovation adoption. Health Care Management Review, 30(4), 282-292. doi:10. 1097/00004010-200510000-00002.

Canadian Healthcare Association. (2009). New directions for facility-based long term care. Retrieved from https:// www.advantageontario.ca/oanhssdocs/Issue_Positions / External_Resources/Sept2009_New_Directions_for_Facility_ Based_LTC.pdf

Carter, S. E., \& Currie-Alder, B. (2006). Scaling-up natural resource management: Insights from research in Latin America. Development in Practice, 16(2), 128-140. doi:10. 1080/09614520600562306.

Collins, C., Green, A., \& Hunter, D. (1999). Health sector reform and the interpretation of policy context. Health Policy, 47(1), 69-83. doi:10.1016/S0168-8510(99)00003-2.
Cranley, L. A., Keefe, J. M., Taylor, D., Thompson, G., Beacom, A. M., Squires, J. E., Estabrooks, C. A., Dearing, J. W., Norton, P. G., \& Berta, W. B. (2019). Understanding professional advice networks in long-term care: An outside-inside view of best practice pathways for diffusion. Implementation Science, 14(1), Article 10. doi: 10.1186/s13012-019-0858-6

Darr, E. D., \& Kurtzberg, T. R. (2000). An investigation of partner similarity dimensions on knowledge transfer. Organizational Behavior and Human Decision Processes, 82 (1), 28-44. doi:10.1006/obhd.2000.2885.

Dearing, J. W. (2009). Applying diffusion of innovation theory to intervention development. Research on Social Work Practice, 19(5), 503-518. doi:10.1177/1049731509335569.

Dearing, J. W., Beacom, A. M., Chamberlain, S. A., Meng, J., Berta, W. B., Keefe, J. M., \& Estabrooks, C. A. (2017). Pathways for best practice diffusion: The structure of informal relationships in Canada's long-term care sector. Implementation Science, 12(1), 11. doi:10.1186/ s13012-017-0542-7.

Domínguez, S., \& Hollstein, B. (2014). Mixed methods social networks research: Design and applications. New York, NY: Cambridge University Press.

Ferlie, E., Fitzgerald, L., Wood, M., \& Hawkins, C. (2005). The nonspread of innovations: The mediating role of professionals. The Academy of Management Journal, 48(1), 117-134. doi:10.5465/amj.2005.15993150.

Frenk, J. (1995). Comprehensive policy analysis for health system reform. Health Policy, 32(1-3), 257-277. doi:10. 1016/0168-8510(95)00739-F.

Giddens, A. (1985). Time, space and regionalization. In D. Gregory \& J. Urry (Eds.), Social relations and spatial structures (pp. 265-295). London, ENG: MacMillan.

Greenhalgh, T., Robert, G., Bate, P., Macfarlane, F., \& Kyruakidou, O. (2005). Diffusion of innovations in health service organisations: A systematic literature review. Malden, MA: Blackwell.

Haines, V. A. (1988). Social network analysis, structuration theory and the holism-individualism debate. Social Networks, 10(2), 157-182. doi:10.1016/0378-8733(88)90020-2.

Isett, K. R., Mergel, I. A., LeRoux, K., Mischen, P. A., \& Rethemeyer, R. K. (2011). Networks in public administration scholarship: Understanding where we are and where we need to go. Journal of Public Administration Research and Theory, 21(Suppl. 1), i157-i173. doi:10.1093/jopart/muq061.

Keefe, J. M., MacEachern, L., \& Fancey, P. (2017). An overview of residential long-term care in New Brunswick, Nova Scotia, and Prince Edward Island. Retrieved from http:/ / www.msvu.ca/site/media/msvu/Overview\%20of\% 20LTC\%20in\%20Maritimes_June\%202017.pdf

Kim, S., \& Shin, E. -H. (2002). A longitudinal analysis of globalization and regionalization in international trade: 
A social network approach. Social Forces, 81(2), 445-468. doi:10.1353/sof.2003.0014.

Knoke, D. (2011). Policy networks. In J. Scott \& P. J. Carrington (Eds.), The SAGE handbook of social network analysis (pp. 210-222). London, ENG: Sage.

Lanham, H. J., Leykum, L. K., Taylor, B. S., McCannon, C. J., Lindberg, C., \& Lester, R. T. (2013). How complexity science can inform scale-up and spread in health care: Understanding the role of self-organization in variation across local contexts. Social Science E Medicine, 93, 194-202. doi:10.1016/j.socscimed.2012.05.040.

Lecy, J. D., Mergel, I. A., \& Schmitz, H. P. (2014). Networks in public administration: Current scholarship in review. Public Management Review, 16(5), 643-665. doi:10. 1080/14719037.2012.743577.

Lucas, J. A., Avi-Itzhak, T., Robinson, J. P., Morris, C. G., Koren, M. J., \& Reinhard, S. C. (2005). Continuous quality improvement as an innovation: Which nursing facilities adopt it? The Gerontologist, 45(1), 68-77. doi:10. 1093 / geront/45.1.68.

Mascia, D., Di Vincenzo, F., Iacopino, V., Fantini, M. P., \& Cicchetti, A. (2015). Unfolding similarity in interphysician networks: The impact of institutional and professional homophily. BMC Health Services Research, 15(1), 92. doi:10.1186/s12913-015-0748-9.

McPherson, M., Smith-Lovin, L., \& Cook, J. M. (2001). Birds of a feather: Homophily in social networks. Annual Review of Sociology, 27(1), 415-444. doi:10.1146/annurev.soc.27.1. 415 .

O'Toole, L. J. (2015). Networks and networking: The public administrative agendas. Public Administration Review, 75 (3), 361-371. doi:10.1111/puar.12281.

Palinkas, L. A., Holloway, I. W., Rice, E., Fuentes, D., Wu, Q., \& Chamberlain, P. (2011). Social networks and implementation of evidence-based practices in public youth-serving systems: A mixed-methods study. Implementation Science, 6(1), Article 113. doi:10. 1186/1748-5908-6-113

Phelps, C., Heidl, R., \& Wadhwa, A. (2012). Knowledge, networks, and knowledge networks: A review and research agenda. Journal of Management, 38(4), 1115-1166. doi:10.1177/0149206311432640.

Pow, J., Gayen, K., Elliott, L., \& Raeside, R. (2012). Understanding complex interactions using social network analysis. Journal of Clinical Nursing, 21(19pt20), 2772-2779. doi:10.1111/j.1365-2702.2011.04036.x
Provan, K. G., \& Milward, H. B. (1995). A preliminary theory of interorganizational network effectiveness: A network study of four community mental health systems. Administrative Science Quarterly, 40(1), 1-33. doi:10. $2307 / 2393698$.

Reagans, R. (2011). Close encounters: Analyzing how social similarity and propinquity contribute to strong network connections. Organization Science, 22(4), 835-849. doi:10. 1287 / orsc. 1100.0587

Rhodes, R. A. W. (2006). Policy network analysis. In M. Moran, M. Rein, \& R. R. Goodin (Eds.), The Oxford handbook of public policy (pp. 425-447). Oxford, ENG: Oxford University Press.

Rogers, E. M. (1983). Diffusion of innovations (3rd ed.). New York, NY: The Free Press.

Schoen, M. W., Moreland-Russell, S., Prewitt, K., \& Carothers, B. J. (2014). Social network analysis of public health programs to measure partnership. Social Science $\mathcal{E}$ Medicine, 123, 90-95. doi:10.1016/j.socscimed.2014.10.057.

Statistics Canada. (2017). Age and sex, and type of dwelling data: Key results from the 2016 Census. Retrieved from https: / / www150.statcan.gc.ca/n1/daily-quotidien/170503/dq170 503a-eng.pdf

Szulanski, G. (1996). Exploring internal stickiness: Impediments to the transfer of best practice within the firm. Strategic Management Journal, 17(S2), 27-43. doi:10. 1002/smj.4250171105.

Valente, T. W., Palinkas, L. A., Czaja, S., Chu, K. -H., \& Hendricks Brown, C. (2015). Social network analysis for program implementation. PLOS ONE, 10(6), e0131712. doi:10.1371/journal.pone.0131712

von Hippel, E. (1994). "Sticky information" and the locus of problem solving: Implications for innovation. Management Science, 40(4), 429-439. doi:10.1287/mnsc. 40.4.429

Walker, M. E., Wasserman, S., \& Wellman, B. (1994). Statistical models for social support networks. In S. Wasserman \& J. Galaskiewicz (Eds.), Advances in social network analysis: Research in the social and behavioural sciences (pp. 53-78). Thousand Oaks, CA: Sage.

Yaraghi, N., Du, A. Y., Sharman, R., Gopal, R. D., Ramesh, R., Singh, R., \& Singh, G. (2014). Professional and geographical network effects on healthcare information exchange growth: Does proximity really matter? Journal of the American Medical Informatics Association, 21(4), 671-678. doi:10.1136/amiajnl-2012-001293. 